\title{
Prescribing patterns of antibiotics outpatients received by pharmacies in Medan city, Indonesia in 2017
}

\author{
Khairunnisa* iD , Embun Suci Nasution \\ Department of Pharmacology, Faculty of Pharmacy, Universitas Sumatera Utara, Indonesia
}

\begin{abstract}
Introduction: This study aimed to determine the patterns of antibiotic use from prescriptions of physicians received by pharmacies in Medan from January to March 2017.

Methods: This study was conducted in a cross-sectional method using direct observation of prescriptions received by 100 pharmacies in Medan city. The data obtained were analyzed descriptively and grouped based on the antibiotic names, antibiotic classes, type of drugs, dosage forms and prescriptions.

Results: A total of 12,388 prescription sheets were obtained from 100 pharmacies in Medan during the study period in which 3,823 of the prescription sheets $(30.96 \%)$ contained antibiotics. According to the data, 4,029 antibiotics were prescribed by physicians in which amoxicillin (20.63\%) and cephalosporin groups (25.94\%) as the most widely prescribed antibiotic and antibiotic class, respectively. A total of 1,923 antibiotics (47.73\%) were prescribed with generic names and more than half of the antibiotics were prescribed in the dosage form of tablets $(65.65 \%)$. This study also found that Ear Nose Throat (ENT) specialists are medical doctors who prescribe antibiotics the most.
\end{abstract}

Conclusion: Based on the study results, it can be concluded that the frequency of antibiotic prescriptions is still quite high in which amoxicillin as the most commonly prescribed antibiotic. In addition, ENT specialists as the most frequent prescribers of antibiotics.

http://dx.doi.org/10.32598/ppj.24.1.40

\section{Keywords:}

Antibiotics;

Drug use patterns;

Pharmacy;

Prescription

\author{
* Corresponding author: \\ Khairunnisa \\ Email: \\ khairunnisa7@usu.ac.id \\ Received 20 March 2019; \\ Received in revised form 20 \\ October 2019; Accepted 23 \\ October 2019
}

\section{Introduction}

Infection-induced diseases continue to be a common cause of pain and death throughout the world in both developing and developed countries (Gupta and Guin, 2010). Indonesia is one of the countries in Southeast Asia which has a tropical climate and dense population in several regions. This situation can increase the incidence of infectious diseases, such as acute respiratory infections, diarrhea, typhus, pharyngitis, tonsillitis and tuberculosis (Dhillon et al., 2012). As a result, the use of antibiotics becomes inevitable and widely used to treat infectious diseases.

Several studies have shown that antibiotics are widely used and become the most commonly prescribed drugs in clinics, hospitals and communities. For example, a study in Yemen 
reported that more than $80 \%$ of prescriptions received from out patient clinics from four hospitals contained antibiotics (Alshakka et al., 2016). Another study in Pakistan also found that $50 \%$ of prescriptions given by physicians contained antibiotics (Raza et al., 2014). Similarly, evaluative research conducted in Indonesia about the use of drugs prescribed at the Community Health Centers in Java showed that almost $40 \%$ of prescriptions contained antibiotics (Munaf, 2005). A 16\% of individuals in Indonesia who had been interviewed in public healthcare facilities took antibiotics (Hadi et al., 2008). Furthermore, another study conducted in the community health centers in Depok found that the percentage of prescriptions containing antibiotics was slightly high at around 28.2\% (Andrajati et al., 2017). Based on the indicators of drug use issued by World Health Organization (WHO), a prescription is indicated good if the prescription contains antibiotics between 2027\% (Shankar, 2009).

The most important thing in the use of antibiotics is the rationality of its use. If antibiotics are used irrationally, it will cause a more dangerous problem where bacteria become resistant to antibiotics. In addition, the irrational use of antibiotics can increase the incidence of illness, death, costs and side effects (Bbosa et al., 2014). The inaccurate use of antibiotics might be because of a lack of regulation and firmness in the use of antibiotics. In reality, antibiotics can be obtained without a prescription. A study in Yogyakarta found that $7.3 \%$ of antibiotics were used for self-medication (Widayati et al., 2011). In fact, antibiotics are drugs that can be obtained only by prescriptions (Rachmawati et al., 2014).

Antibiotic resistance has recently become one of the world's health problems. This is due to the low percentage of treatment success and increased health costs because bacterial infections are more difficult to treat (Bbosa et al., 2014; Rachmawati et al., 2014; Shamsuddin et al., 2016; Ain et al., 2010). Nearly $64 \%$ of prescribed antibiotics have no indication, incorrect indication or improper dose. In addition, other studies showed that $50 \%$ of antibiotics prescribed in hospitals were often not necessary (Grosso et al., 2012; Abdulah, 2012). Other data also indicated that the high use of antibiotics was aimed to treat infections caused by viruses (Abdulah, 2012).

Research on drug use in general aims to assess the rationality of drug use. There are three purposes in the studies of drug use, such as to describe patterns of the drug use, to resolve problems related to the drug use and to monitor drug use from time to time (Shamsuddin et al., 2016). The majority of research and data available in the use of drugs either antibiotics or other drugs were only conducted in hospitals and community health centers, especially in Indonesia (Munaf, 2005; Andrajati et al., 2017; Pradipta et al., 2015). In the current treatment system in Indonesia, people will check their conditions in the first health facilities such as community health centers, clinics or physician practices when they feel sick.

However, research on drugs prescription, specifically antibiotics by physician practices received by pharmacies is still limited, especially in Medan. Medan City is known as the third largest city in Indonesia after Jakarta and Surabaya, and the largest city outside Java. Various ethnic groups live together in this city such as Batak, Malay, Javanese and others. Medan consists of 21 subdistricts with a population of more than 2 million people. Based on information from the Medan City branch of the Indonesian Pharmacist Association, there are approximately 600 pharmacies in 21 subdistricts. Therefore, a study about the patterns of drug use especially antibiotics in prescriptions received by pharmacies in Medan is needed.

\section{Materials and methods}

The present research was conducted in Medan City, Indonesia in which 100 pharmacies from 21 subdistricts were involved. The pharmacies involved were selected randomly and proportionally, hence it could represent all subdistricts of Medan City. This research was a cross-sectional study with a retrospective observation method and data from prescriptions received by 100 pharmacies in Medan within 3 months from January to March 2017. Data collection was done by collecting the entire prescription sheets received by the selected pharmacies in the specified month. After that, the selection was carried out based on the inclusion criteria, such as prescriptions containing antibiotics and obtained from physician practices. Prescriptions which did not contain antibiotics and came from hospitals did not become samples in this research. The prescriptions which fulfilled the inclusion criteria was analysed using WHO indicator which consisted 
antibiotic names, dosage forms, types of drug (generic and non-generic) and prescribers (origin of the prescription). The data obtained were analyze during descriptive statistics and described using tables containing the number and percentage of use. The method of the study was approved by health research ethics committee, Faculty of Nursing, Universitas Sumatera Utara (Formal Approval Number: 1281/IX/SP/2017).

\section{Results}

A total of 12,338 prescription sheets were obtained from 100 pharmacies involved in the study. The prescriptions were received within 3 months of study (January-March 2017). Among those, 31\% of the prescriptions were prescriptions containing antibiotics (3,823 sheets). Among 3,823 prescription sheets containing antibiotics, the study found that 4,029 antibiotics consisted of 31 types of antibiotics. The most widely used or prescribed antibiotics in Medan were amoxicillin with 831 prescriptions (20.36\%), followed by cefadroxil with 612 prescriptions (15.21\%) and ciprofloxacin with 549 prescriptions $(13.63 \%)$. Based on the antibiotic classes, the most widely used antibiotic was the cephalosporin class with 1,045 prescriptions (25.94\%), followed by penicillin with 1,004 prescriptions (24.91\%) and fluoroquinolone with 873 prescriptions (21.67\%). The complete data is presented in Tables 1 and 2 .

The results also depicted that the prescriptions received by pharmacies in Medan were written by general practitioners and specialists. The Ear Nose Throat (ENT) specialist were the specialists who prescribe antibiotics the most with 1,108 prescriptions (27.50\%), followed by general practitioner with 999 prescriptions $(24,79 \%)$ and dentists with 722 prescriptions $(17,97 \%)$. The complete data is shown in Table 3.

Based on the types of drugs often prescribed, this study showed that the use of generic or no branded drugs was relatively high among private-practice physicians in Medan. In this study, the use of nongeneric drugs was 2,106 (52.27\%) whereas the use of generic drugs was $1,923(47.73 \%)$. The data can be found in Table 4.

Table 5 shows the dosage forms of antibiotics, which are often prescribed based on prescriptions received by pharmacies in Medan City. The study found that

Table 1: The most commonly prescribed antibiotics.

\begin{tabular}{lcc}
\hline Name of drug & $\mathrm{N}$ & Percentages \\
\hline Amoxicillin & 831 & 20.63 \\
Cephadroxil & 613 & 15.21 \\
Ciprofloxacin & 549 & 13.63 \\
Cefixime & 373 & 9.26 \\
Levofloxacin & 295 & 7.32 \\
Rifampicin & 235 & 5.83 \\
Clindamycin & 232 & 5.76 \\
Amoxicillin and clavulanate & 172 & 4.44 \\
Isoniazid & 139 & 3.45 \\
Thiamphenicol & 71 & 1.76 \\
\hline
\end{tabular}

Table 2: The most commonly prescribed antibiotic classes.

\begin{tabular}{lcc}
\hline Antibiotic class & $\mathrm{N}$ & Percentages \\
\hline Cephalosporins & 1045 & 25.94 \\
Penicillins & 1004 & 24.91 \\
Fluoroquinolones & 873 & 21.67 \\
Anti -Tuberculosis & 441 & 10.95 \\
Macrolides & 408 & 10.13 \\
\hline
\end{tabular}


Table 3: List of the most often prescribers of antibiotics.

\begin{tabular}{lcc}
\hline Prescriber & $\mathrm{N}$ & Percentages \\
\hline ENT Specialists & 1108 & 27.50 \\
General Practitioners & 999 & 24.79 \\
Dentists & 722 & 17.92 \\
Internists & 698 & 17.32 \\
Pediatricians & 296 & 7.35 \\
Obstetricians\& Gynecologists & 81 & 2.01 \\
Dermatovenereology & 75 & 1.86 \\
Neurologists & 17 & 0.42 \\
Ophthalmologists & 11 & 0.27 \\
Others & 22 & 5.46
\end{tabular}

Table 4: The most often prescribed types of drugs.

\begin{tabular}{lcc}
\hline Type of Drug & N & Percentages \\
\hline Generic & 1923 & 47.73 \\
Non-Generic & 2106 & 52.27 \\
\hline
\end{tabular}

Table 5: The most often prescribed drug dosage forms.

\begin{tabular}{lll}
\hline Dosage Form & $\mathrm{N}$ & Percentages \\
\hline Tablets & 2645 & 65.65 \\
Capsules & 504 & 12.51 \\
Suspension/Syrups & 441 & 10.95 \\
Powder & 235 & 5.83 \\
Ear and eyedrops & 114 & 2.83 \\
Injections & 62 & 1.54 \\
Cream/Topical ointment & 27 & 0.67 \\
Suppository & 1 & 0.02 \\
\hline
\end{tabular}

the most prescribed dosage forms were the forms which were used orally, such as tablets, capsules, syrups and powder with $94.94 \%$ of the total prescribed drugs. Other commonly prescribed dosage forms were eye and ear drops (2.83\%), injections (1.54\%) and topical forms such as cream $(0.67 \%)$.

\section{Discussion}

The study results indicated that the percentage of antibiotic prescriptions is still relatively high in Medan City with $31 \%$. This percentage is higher than the indicator of drug prescriptions containing antibiotics based on the WHO, which is approximately $20-27 \%$ (Shankar, 2009). The high use of antibiotics can increase the occurrence of antibiotic resistance to bacteria which may result in a problem among the public. The high use of antibiotics implies that strict regulation is needed in prescribing it (Desalegn, 2013). To make regulations about the use and prescription of antibiotics, sufficient knowledge about the factors which can influence is required. Hence, it can improve the rationality of prescribing antibiotics (Pradipta et al., 2015). Factors which can influence the use of antibiotics and should be considered are the prescribers, patients, facilities and regulations 
(Kotwani et al., 2010). Prescribers are the most important factors in prescribing drugs including antibiotics. This factor is influenced by the knowledge of the prescribers, difficulties in diagnosing the disease, patients demand and financial factors (Kotwani et al., 2010).

This study found that the most commonly prescribed antibiotics are broad-spectrum antibiotics such as amoxicillin, cefadroxil, ciprofloxacin and cefixime. This is understandable because almost all antibiotics are prescribed based on empirical therapy because private-practice physicians do not perform culture tests in prescribing antibiotics (Shamsuddin et al., 2016). The most commonly prescribed antibiotic is amoxicillin with 831 prescriptions (20.63\%). This result is in line with several other studies which also found that the most commonly prescribed type of antibiotic is amoxicillin (Ain et al., 2010; Grosso et al., 2012; Pradipta et al., 2015; Desalegn, 2013).

Amoxicillin is a drug that often becomes the main choice by physicians in treating various types of infectious diseases in almost all regions. The reason for choosing amoxicillin is that this drug has a safe profile to use in treatment for both paediatric and adult patients. The high therapeutic effectiveness for both local and systemic infections, low side effects, high safety, lower prices and availability in various dosage forms with different strengths are several reasons of why prescribers tend to write amoxicillin as the antibiotic compared to other antibiotics (Thambavita et al., 2017).

This study also found that prescriptions containing antibiotics received by pharmacies in Medan City came from various medical specialist backgrounds. The ENT specialists were the most often prescribers of antibiotics, followed by general practitioners and dentists. Upper respiratory tract infections, such as tonsillitis, pharyngitis, laryngitis and otitis media are infectious diseases that commonly use antibiotics in their treatment. In addition, infectious diseases which are often indicated in the use of antibiotics are tuberculosis and oral cavity (Andrajati et al., 2017; Rachmawati et al., 2014; Shamsuddin et al., 2016).

One of indicators medicine use in medical school based on WHO is the amount of generic drugs. However, the use of generic drugs is also suggested in private hospitals, clinics and private-practice physicians. This regulation is expected to reduce medical costs that must be incurred by patients, especially in the provision of medicines. In this study, the use of antibiotic drugs with generic names was only $47.73 \%$ while the use of non-generic names was $52.27 \%$. The use of non-generic drugs will directly increase the direct cost of a drug or the drug price. Health care costs have an important role in the market economy and patient compliance. Marketing and promotion activities influence the practice of prescribing drugs among physicians (Abdulah, 2012). Based on the dosage forms, the results showed that most of the antibiotics used in this study were antibiotics used orally, such as tablets, capsules, syrups and powder. Moreover, the dosage forms used orally were the most common dosage forms for patients, especially for outpatients. This is because oral preparations are easy to use by these patients and do not require the help of health professionals in using the drugs. Tablets or capsules are usually given for adult patients whereas syrups and powder usually used by paediatric and elderly patients. Tablets and capsules are conventional dosage forms that are widely produced by pharmaceutical industries. Furthermore, tablets and capsules have better stability and lower production costs. Eventually, the prices of antibiotics in these dosage forms are more affordable to the public (Lopez et al., 2015).

\section{Conclusion}

Antibiotic prescriptions received by pharmacies in Medan City were still relatively high in which amoxicillin was the most commonly prescribed type of antibiotics. The use of drugs with generic names was still low among physicians in private practice so that it can increase the cost of treating a disease.

\section{Acknowledgments}

The authors would like to thank the University of Sumatera Utara (USU) for the research scheme TALENTA 2017 with contract No: 5338/UN5.1.R/PPM/2017.

\section{Conflict of interest}

The authors have no conflict of interest to declare.

\section{References}

Abdulah R. Antibiotic abuse in developing countries. Pharmaceut Reg Affairs 2012; 2: 1000e106. https://dx.doi.org/10.4172/2167-7689.1000e106

Ain MR, Shahzad N, Aqil M, Alam MS, Khanam R. Drug 
utilization pattern of antibacterials used in ear, nose and throat outpatient and inpatient departments of a university hospital at New Delhi, India. J Pharm Bioallied Sci 2010; 1: 8-12. https://dx.doi.org/10.4103/ 0975-7406.62695

Alshakka M, Said K, Babakri M, Ansari M, Aldhubhani A, Hassali MA, et al. A study on antibiotics prescribing pattern at outpatient department in four hospitals in Aden-Yemen. J Pharm Pract Community Med 2016; 2: 88-93. https://dx.doi.org/10.5530/jppcm.2016.3.5

Andrajati R, Tilaqza A, Supardi S. Factors related to rational antibiotic prescriptions in community health centers in Depok City, Indonesia. J Infect Public Health 2017; 10: 41-48. https://doi.org/10.1016/j.jiph.2016. 01.012

Bbosa GS, Wong G, Kyegombe DB, Ogwal-Okeng J. Effects of intervention measures on irrational antibiotics/antibacterial drug use in developing countries: a systematic review. Health 2014; 2: 171 187. https://dx.doi.org/10.4236/health.2014.62027

Desalegn AA. Assessment of drug use pattern using WHO prescribing indicators at Hawassa University Teaching and Referral Hospital, south Ethiopia: a cross-sectional study. BMC Health Serv Res 2013; 13: 170. https://doi.org/10.1186/1472-6963-13-170

Dhillon PK, Jeemon P, Arora NK, Mathur P, Maskey M, Sukirna RD, et al. Status of epidemiology in the WHO South-East Asia region: burden of disease, determinants of health and epidemiological research, workforce and training capacity. Int J Epidemiol 2012; 41: 847-60. https://doi.org/10.1093/ije/dys046

Grosso G, Marventano S, Ferranti R, Mistretta A. Pattern of antibiotic use in the community: von-adherence and self-prescription rates in an Italian urban population. Mol Med Rep 2012; 5: 1305-10. https://doi.org/10.3892/ mmr.2012.818

Gupta I, Guin P. Communicable diseases in the South-East Asia Region of the World Health Organization: towards a more effective response. Bull World Health Organ 2010; 88: 199-205. https://doi.org/10.2471/BLT.09. 065540

Hadi U, Duerink DO, Lestari ES, Nagelkerike NJ, Werter S, Keuter M, et al. Survey of antibiotic use of individuals visiting public healthcare facilities in Indonesia. Int $\mathrm{J}$ Infect Dis 2008; 12: 622-9. https://doi.org/10.1016/ j.ijid.2008.01.002
Kotwani A, Wattal C, Katewa S, Joshic PC, Holloway K. Factors influencing primary care physicians to prescribe antibiotics in Delhi India. Fam Pract 2010; 27: 684-90. https://doi.org/10.1093/fampra/cmq059

Lopez FL, Ernest TB, Tuleu C, Gul MO. Formulation approaches to pediatric oral drug delivery: benefits and limitations of current platforms. Expert Opin Drug Deliv 2015; 12: 1727-40. https://doi.org/10.1517/17425247. 2015.1060218

Munaf S. Antibiotic prescription practices in six primary health centers in South Sumatra. Med J Indonesia 2005; 14: 44-49. https://doi.org/10.13181/mji.v14i1.170

Pradipta IS, Ronasih E, Kartikawati AD, Hartanto H, Amelia $R$, Febrina $E$, et al. Three years of antibacterial consumption in Indonesian Community Health Centers: the application of anatomical therapeutic chemical/defined daily doses and drug utilization $90 \%$ method to monitor antibacterial use. J Family Community Med 2015; 22: 101-5. https://dx.doi.org/ 10.4103/2230-8229.155385

Rachmawati MW, Yoshida N, Tsuboi H, Kimura K. Investigation of antibiotic use at a dental teaching hospital in Yogyakarta, Indonesia: a review from guidelines. Pharmacol Pharm 2014; 5: 524-31. http://dx.doi.org/10.4236/pp.2014.55062

Raza UA, Khursheed T, Irfan M, Abbas M, Irfan UM. Prescription patterns of general practitioners in peshawar, Pakistan. Pak J Med Sci 2014; 30: 462-5. https://dx.doi.org/10.12669/pjms.303.4931

Shamsuddin S, Akkawi ME, Zaidi ST, Ming LC, Manan MM. Antimicrobial drug use in primary healthcare clinics: a retrospective evaluation. Int $\mathrm{J}$ Infect Dis 2016; 52: 1622. https://doi.org/10.1016/j.ijid.2016.09.013

Shankar PR. Medicines use in primary care in developing and transitional countries. Bull World Health Organ 2009; 87: 804. http://doi.org/10.2471/BLT.09.070417

Thambavita D, Galappatthy P, Mannapperuma U, Jayakody $\mathrm{L}$, Cristofoletti R, Abrahamsson B, et al. Biowaiver monograph for immediate-release solid oral dosage forms: amoxicillin trihydrate. J Pharm Sci 2017; 106: 2930-2945. http://dx.doi.org/10.1016/j.xphs.2017.04.068

Widayati A, Suryawati S, de Crespigny C, Hiller JE. Self medication with antibiotics in Yogyakarta City Indonesia: a cross sectional population-based survey. BMC Res Notes 2011; 4: 491. https://doi.org/10.1186/ 1756-0500-4-491 